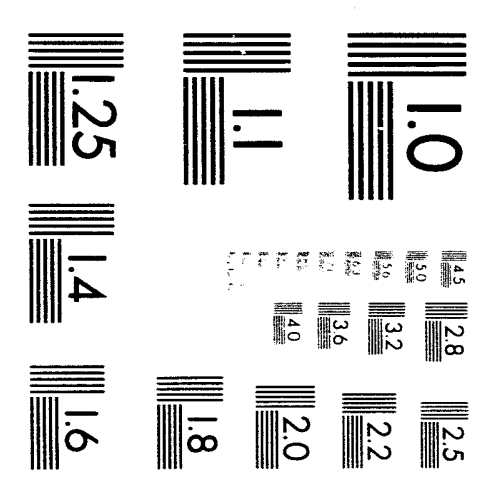



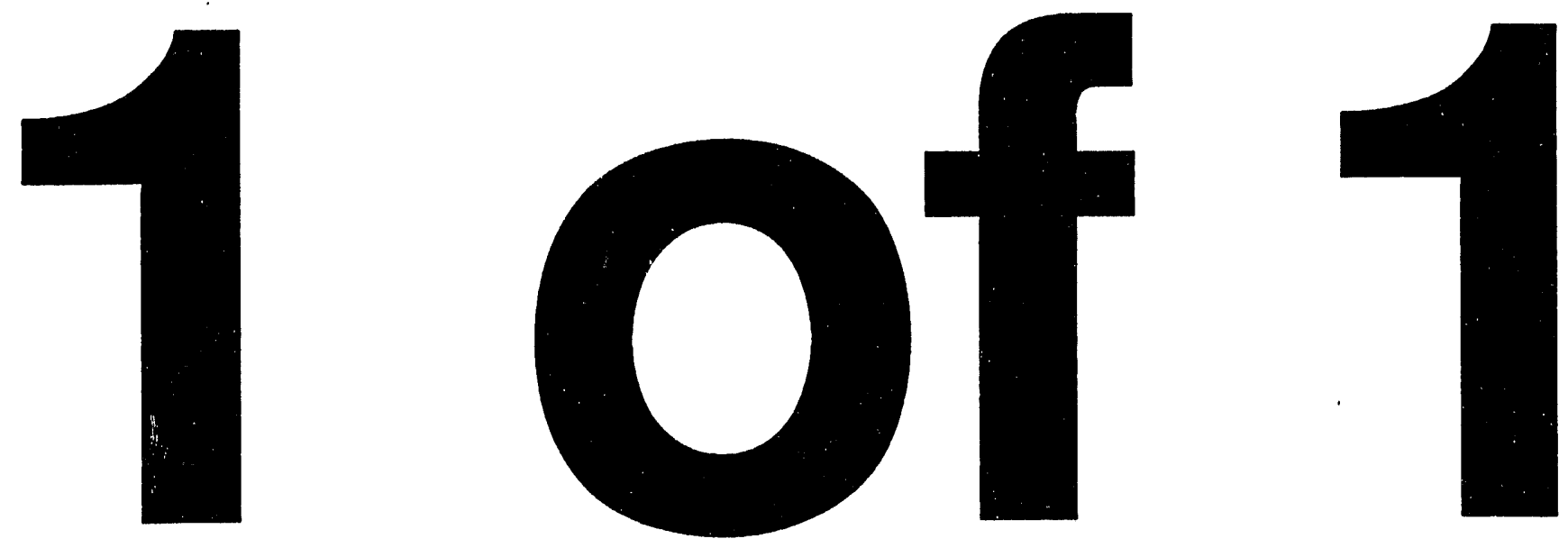


\title{
The TPX
}

\section{Cryostat Conceptual Design}

\author{
D. Ravenscroft, A. Posey \\ Lawrence Livermore National Laboratory \\ P.O 808, 7000 East Avenue, Livermore, California 94550 \\ P. Heitzenroeder \\ Princeton Plasma Physics Laboratory \\ US Route 1-North, Box 451, Princeton, New Jersey 08543 \\ T. Brown \\ Grumman Corporation, Princeton Corporate Center \\ 4 Independence Way, Princeton, New Jersey 08540-6620
}

\begin{abstract}
The TPX (Tokamak Physics Experiment) will be the first tokamak to employ both superconducting TF (toroidal field) and PF (poloidal field) magnets. Consequently, the entire device is located within an evacuated cryostat to provide the necessary thermal barrier between the ambient temperature test cell and the magnets that are cooled by supercritical liquid helium at $5^{\circ} \mathrm{K}$. This paper describes the cryostat design requirements, design concepts, and the cryostat fabrication and installation.
\end{abstract}

\section{INIRODUCTION}

The evacuated TPX cryostat with the attendant thermal shielding provides the necessary environment for operation of the superconducting TF and PF magnets. The cryostat shown in Fig. 1 is approximately $9.7 \mathrm{~m}$ in diameter and $8.7 \mathrm{~m}$ in height. Liquid nitrogen shiclds and multilayer, reflective, polyimide insulation are employed to minimize the heat transfer to the $5^{\circ} \mathrm{K}$ cold mass.

The TPX Cryostat Conceptual Design Review was completed in 1993. The cryostat design and fabrication subcontract has an expected release date of late 1994. The cryostat final assembly and initiation of engineering testing is planned for 1999.

\section{DESIGN REQUIREMENTS}

- Base Pressure: $<1.3 \times 10^{-3} \mathrm{~Pa}\left(10^{-5}\right.$ torr $)$.

- Leak rate: $<160 \mu \mathrm{Pa}-\mathrm{m}^{3} / \mathrm{s}\left(2 \times 10^{-4}\right.$ torr- $\left.1 / \mathrm{sec}\right)$.

- Design over pressure level: $70 \mathrm{KPa}$.

- Cryostat will be designed for and operated at ambient temperature.

- Radiant and convective heat transfer from the ambient temperature cryostat to the cold mass must be minimized.
- Material ncutron activation must be consistent with maintenance requirements.

- Must provide attachments for the structural support of the vacuum vessel and the cold mass.

- Penetrations must be provided for diagnostics, cooling lines for plasma facing components, vacuum vessel heating and cooling lines, plasma heating and current drive systems, and toroidal and poloidal magnet utilities.

- Organic materials must be compatible with the 105 Gy (107 rad) neutron dose.

- Design stresses to be in accordance with the TPX Structural and Cryogenic Criteria Document.

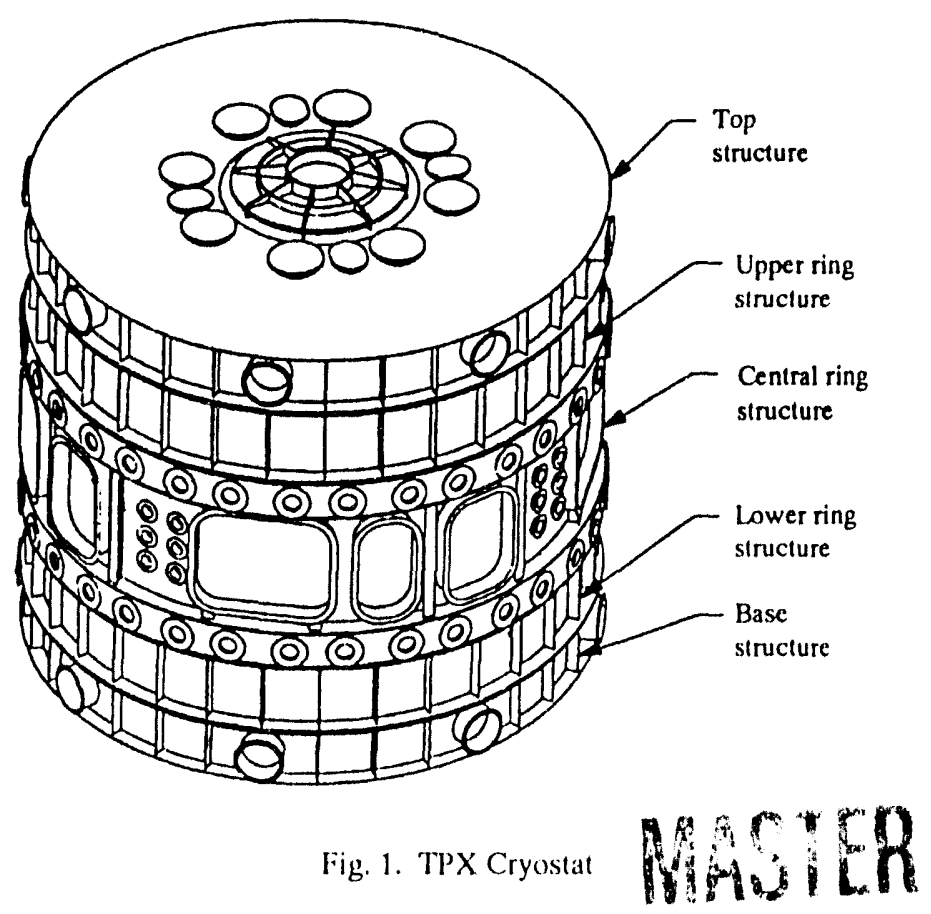




\section{DESIGN CONCEPT}

The cryostat vessel is a bolted and welded structure assembled from the following major subassemblies as shown in Fig. 1:

- a stainless steel top structure.

- a titanium upper ring structure.

- a titanium central ring structure.

- a titanium lower ring structure.

- a stainless steel base structure.

Austenitic 304 stainless steel was chosen for the top and base structures based on its non magnetic properties, strength, and suitability for vacuum service. 6Al4V titanium was chosen for the central ring structures to minimize the activation due to significant neutron fluences in areas where hands-on maintenance is anticipated. Titanium also has the requisite non magnetic propertics, strength, and suitability for vacuum service.

The central hatch provided in the cryostat top structure serves as an entrance to the cryostat, and as a back-up pressure relief device (due to inadvertent pressurization of the cryostat if a cryogen supply line were to break within the cryostat). The hatch cover will be attached by spring-loaded bolts which will permit the hatch to lift and vent if the cryostat is over pressured. Primary pressure relief will be provided via a hinged, sealed "flapper valve" which will be set to vent at a lower pressure.

\section{Penetration Seals}

The cryostat will have a large number of penetrations for diagnostics, cooling lines, bus bars, etc. Typical penetrations are shown for a 90 degree quadrant, developed elevation in Fig. 2. Each of the penetrations must be provided with a seal arrangement which can accommodate both vertical and radial

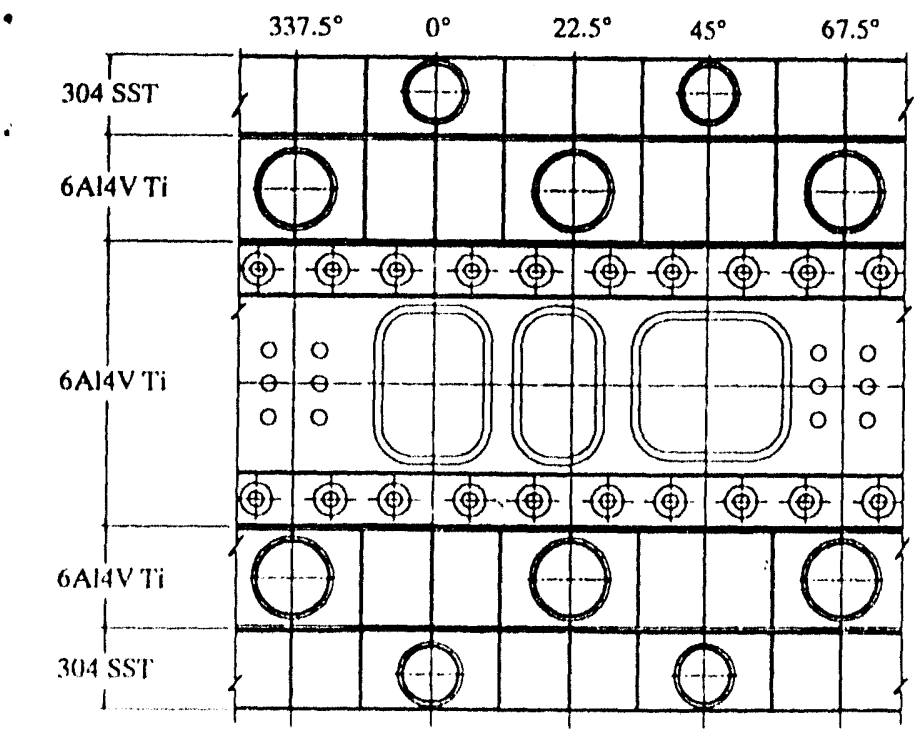

Fig. 2. Developed Elevation of Cryostat Wall displacements due to thermal expansion. The broad range of temperature ranges of the various components in the TPX result in large relative displacements. The vacuum vessel is baked at $350^{\circ} \mathrm{C}$ and operated at $150^{\circ} \mathrm{C}$. The superconducting magnets (cold mass) operate at $-268^{\circ} \mathrm{C}$. In the case of the neutral beam injection ports, the differential vertical displacements are on the order of $10 \mathrm{~mm}$ and the horizontal displacements on the order of $15 \mathrm{~mm}$ during the $350^{\circ} \mathrm{C}$ bakeout of the vacuum vessel. This provides a unique engineering challenge in the case of the TPX, since there are a large number of penetrations with various sizes and configurations all of which require two-axis displacement capability.

The flexible penetration seal design for the large rectangular ports is shown in Fig. 3. A fabric (glass or polyimide) reinforced silicon rubber material is captured within and vulcanized to a titanium frame. Alternative radiation resistant polymers with lower helium permeability are also under consideration. This design was chosen since it is difficult to provide two-axis displacement capability within the stress limit and space constraints with a metal bellows design. The cost would also be considerably higher for the metallic bellows design. Another benefit of the reinforced rubber design is that it inherently provides the dielectric break that is required to avoid electrical current loops. The penetrations will have a breakdown rating of $>1 \mathrm{Kv}$.
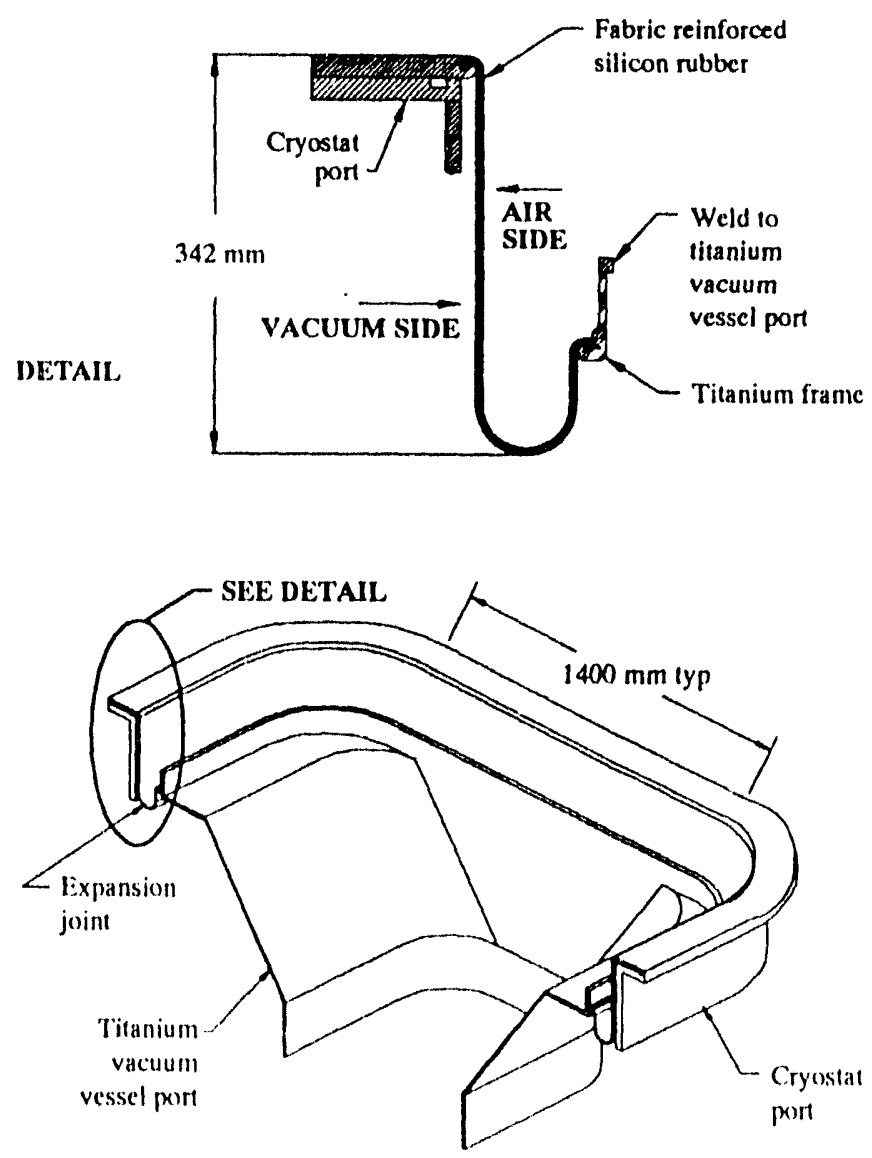

Fïg. 3. Large Penctration Seal Design 


\section{Cryostat Seals}

Circumferential seals will be provided at four places to seal between the base, cylindrical sections, and the cryostat top structure as shown in Fig. 4. The flanges on the cylindri-

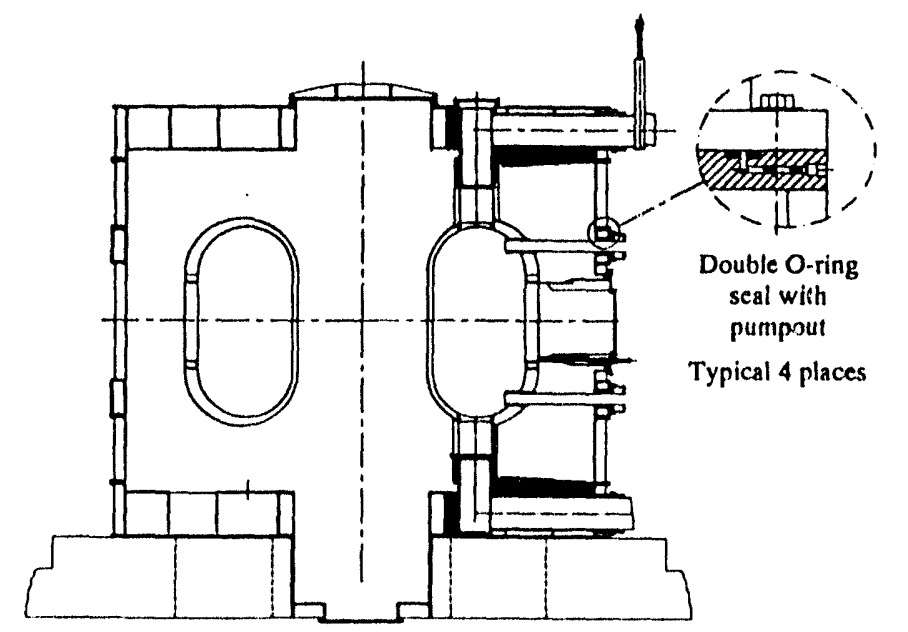

cal sections will be machined to accommodate dual elastomer o-rings. The interspace between the o-rings will be vacuum pumped to facilitate leak testing during cryostat assembly and to provide redundancy. The penetration seal assemblies will be sealed via single - ring seals. Elastomer seals will be nitrile in the high neutron radiation areas, and Viton in the low neutron radiation areas.

\section{THERMAL SHIELDING}

The thermal shielding arrangement is shown in Fig. 5. A nominal ten layers of aluminized, polyimide MLI (multilayer insulation) will minimize radiant heat losses to the cold mass and the cryostat LN (liquid nitrogen) panels. Black LN panels will cover $50 \%$ of the cryostat wall area, $70 \%$ of the ceiling area, and $20 \%$ of the floor area. Additional layers of MLI are used between the cold mass and the vacuum vessel. This arrangement results in a total radiant heat load of $\sim 300$ watts to the cold mass during plasma experiments.

Fig. 4. Cryostat Circumferential Seals

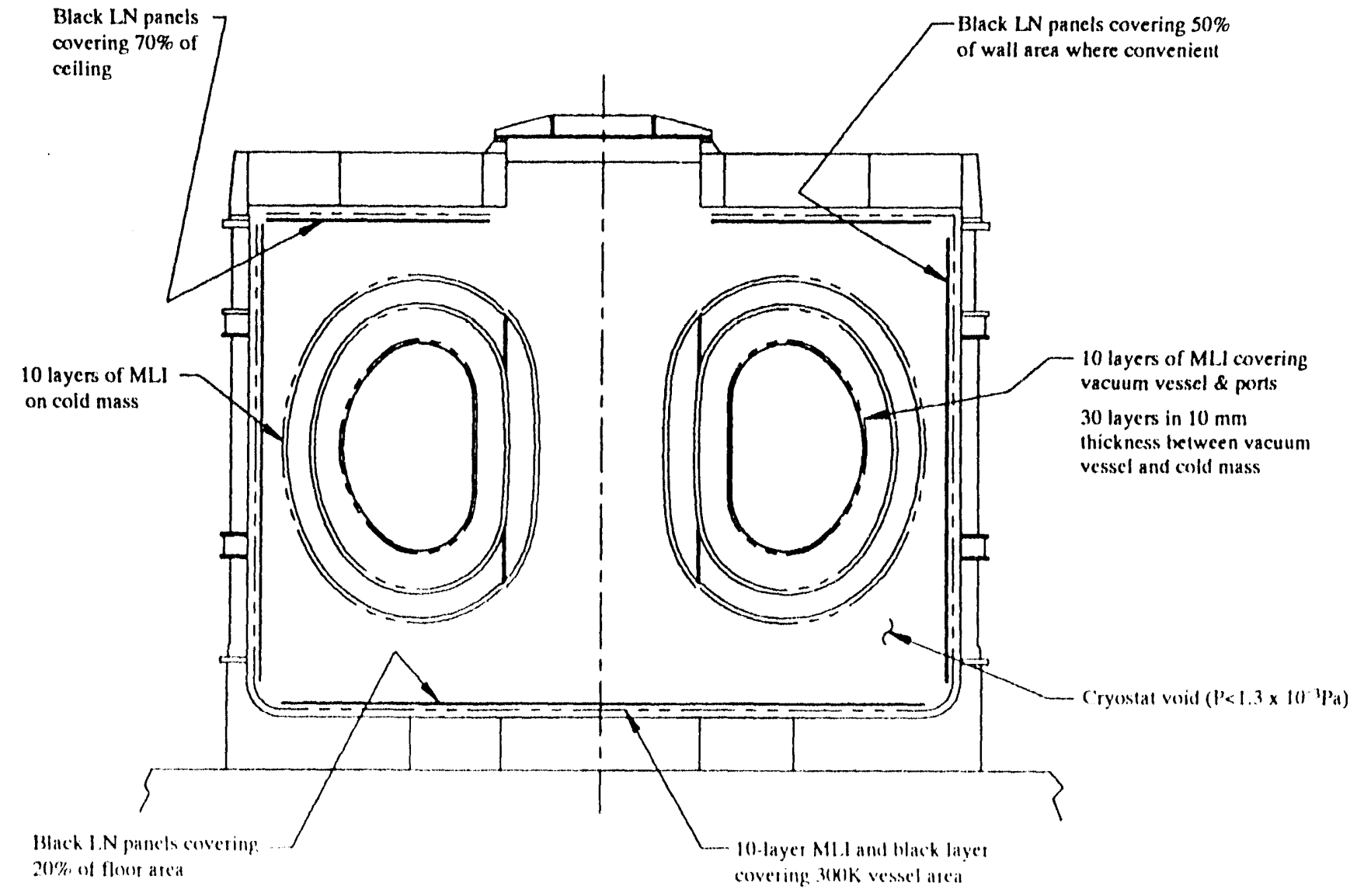

Fe. S. Ciyustat Themal Shichding 


\section{DESIGN LOADS AND ANALYSES}

The TPX cryostat must support the atmospheric loading, the entire mass of the TPX device (estimated at 700 tonne), and the electromagnetic loads due to plasma disruptions. These loads are shown graphically in Fig. 6 . Note that the cryostat base structure acts as a structural tie between the vacuum vessel and the TF coils. This arrangement maximizes thermal decoupling of the vacuum vessel from the $5^{\circ} \mathrm{K}$ cold mass, but requires that the electromagnetic loads resulting from the TF fields interacting with the electrical currents induced in the vacuum vessel during disruption transients be reacted through the cryostat base structure. A finite element analysis (FEA) was performed to provide a preliminary estimate of the stresses in the base structure, which is the most highly stressed portion of the cryostat. The static analysis (excluding the dynamic disruption loads) indicates a maximum deflection of $1.5 \mathrm{~mm}$ and a maximum stress of $\sim 31 \mathrm{MPa}(4.5 \mathrm{ksi})$.

\section{SENSORS}

Sensors will be provided to monitor:

- vacuum total pressure.

- RGA species monitoring including

- helium.

- hydrogen.

- nitrogen

- radiation.

- temperature.

- nitrogen flow.

Additional viewing windows and lighting will be provided to permit observation, both directly and by camera.

$F_{1}$ - External dead weight loads

$F_{2}-$ Vacuum vessel dead weight loads

$\mathrm{F}_{3}$ - Cold mass dead weight loads

$\mathrm{F}_{4}$ - Bearing block reaction loads

$\mathrm{C}_{1}$ - Moments due to disruptive loads are internally reacted within the base

- $\quad P$ - External pressure

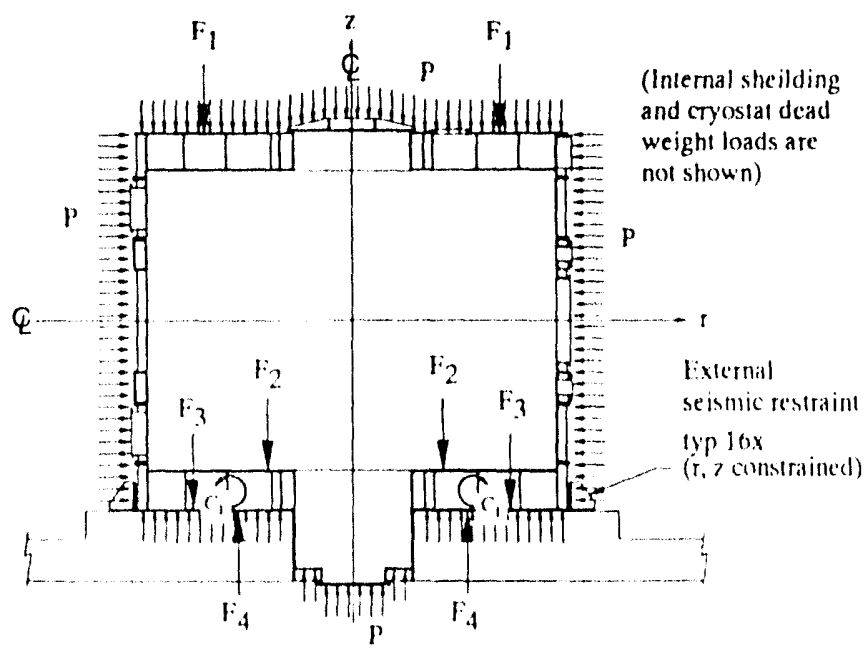

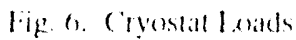

\section{Cryostat Fabrication AND INSTALlation}

The detailed design of the cryostat will be carried out by the fabrication vendor based on TPX project preliminary design and the project supplied specifications. It is anticipated that the cryostat will be field erected from prefabricated 90 degree sectors for each major subassembly. (Prefabrication using larger, 180 degree sectors may be a viable alternative.) The erection assembly operations will be done in the TFTR Test Cell.

Off-site prefabrication will be done to the maximum extent possible, both for efficiency and to permit the Test Cell preparation to be done in parallel with cryostat prefabrication.

The on-site assembly will begin with the base structure. The four 90 degrec (or two 180 degrec) stainless stecl base sectors will be welded together, final machined, and lifted onto the Test Cell platform on which TFTR was previously mounted. The base will be bolted and / or welded to the platform radial bcams to provide a structural tic and scismic restraint.

The threc cylindrical titanium ring structures will require specialized weld procedures. Each ring structure will be welded together from four 90 degree (or two $180 \mathrm{degrcc}$ ) sectors. The large circumferential sealing flanges will be machined on-site to provide the finished sealing surfaces. Scals will be installed and leak checked as each of the ring structures is scquentially stacked.

The stainless steel top structure will be welded together from sectors, final machined, and installed to complete the cryostat assembly in the Test Cell.

The cryostat will be vacuum leak tested to verify its integrity prior to installation of the internal components. Temporary carbon stecl port covers will be installed to seal all ports for vacuum leak testing. The cryostat must have a demonstrated leak rate of $<160 \mu \mathrm{Pa}-\mathrm{m}^{3} / \mathrm{s}\left(2 \times 10^{-4}\right.$ torr- $\left.-1 / \mathrm{sec}\right)$ before acceptance by the TPX program.

\section{CONCLUSIONS}

The cryostat conceptual design including the materials sclection, the large penetration scals, and the thermal shiclding plan have been reviewed by industry and the community. TPX is now ready to proceed with the preliminary design for the eryostat.

\section{ACKNOWIIDGMENTS}

This work was performed under the auspices of the U.S. Department of Inergy by Lawrence Livermore National laboratory under contract number W-74015-1EN( -48 .

This work was supported by U.S. Department of lenergy by Princeton Plasmal Physics l aboratory under Contrad No. D)I:A(C)2-70-(1133173. 

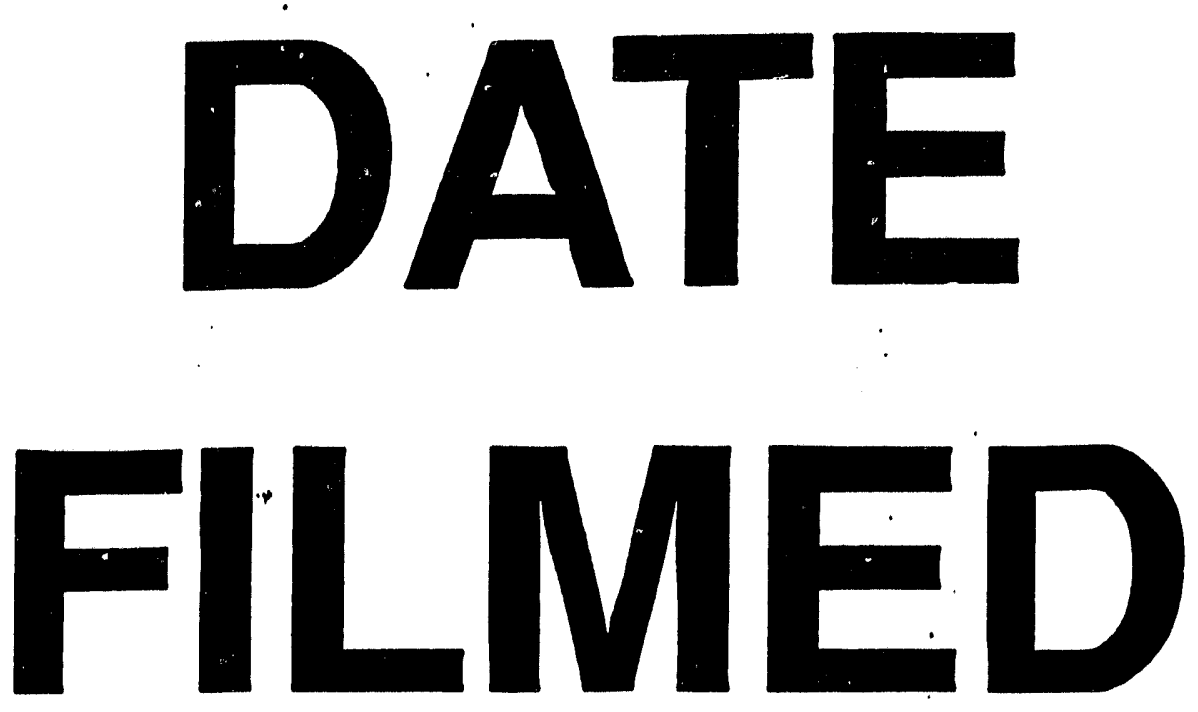

$12 / 29 / 93$
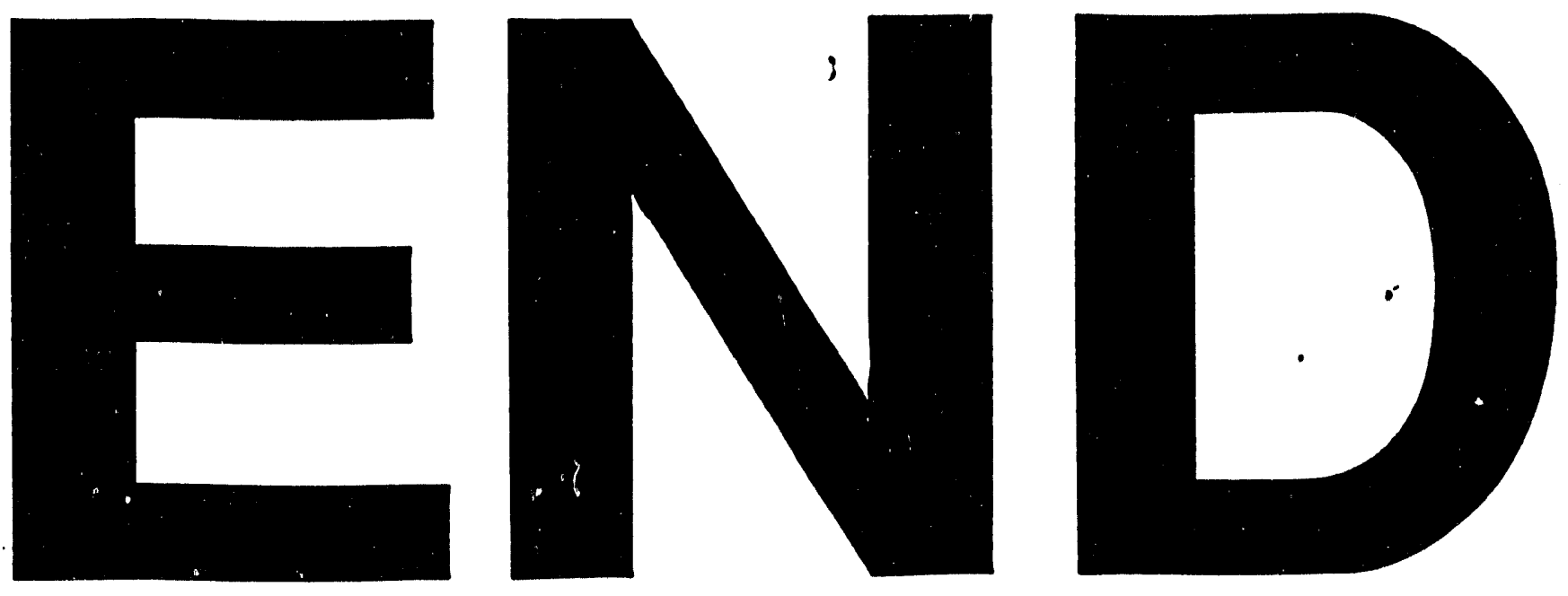
